Umeda, Shinya; Yamazaki, Tatsuo; Yuhi, M.

An Experimental Study of Scour Process and Sediment Transport around a Bridge Pier with Foundation

Verfügbar unter / Available at:

https://hdl.handle.net/20.500.11970/100211

Vorgeschlagene Zitierweise / Suggested citation:

Umeda, Shinya; Yamazaki, Tatsuo; Yuhi, M. (2010): An Experimental Study of Scour Process and Sediment Transport around a Bridge Pier with Foundation. In: Burns, Susan E.; Bhatia, Shobha K.; Avila, Catherine M. C.; Hunt, Beatrice E. (Hg.): Proceedings 5th International Conference on Scour and Erosion (ICSE-5), November 7-10, 2010, San Francisco, USA. Reston, Va.: American Society of Civil Engineers. S. 66-75. 


\title{
An Experimental Study of Scour Process and Sediment Transport around a Bridge Pier with Foundation
}

\author{
S. Umeda ${ }^{1}$, T. Yamazaki ${ }^{2}$ and M. Yuhi ${ }^{3}$
}

\begin{abstract}
${ }^{1}$ School of Environmental Design, Kanazawa University, Kakuma-machi, Kanazawa, 920-1192, Japan; Tel.:+81-76-234-4606; e-mail:umeda@t.kanazawa-u.ac.jp

${ }^{2}$ Kanto branch office, East Japan Expressway Ltd., 2-101-1, Banshoumen, Misato, 341-0056, Japan; Tel.:+81-48-952-8561; e-mail: t.yamazaki.ae@e-nexco.co.jp

${ }^{3}$ School of Environmental Design, Kanazawa University, Kakuma-machi, Kanazawa, 920-1192, Japan; Tel.:+81-76-234-4609; e-mail: yuhi@t.kanazawa-u.ac.jp
\end{abstract}

\begin{abstract}
Laboratory experiments were conducted on the time development of clear water scour around a non-uniform cylindrical pier in steady flow. The pier comprised a slender cylinder founded on a large cylinder. This study aimed at investigating the effects of foundation depth on the scour process. Three-dimensional topography of the scour was carefully measured using digital stereo-photogrammetry as a method to level a riverbed. The spatial distributions of the sediment transport rate were estimated with the variation in the bed elevation. The results show that the process of sediment transport and scour depends on the foundation depth. The retarding and limiting the scour due to the foundation occur when it is placed at an appropriate level below the initial bed level. The scour depth increases with foundation level when the foundation protrudes above the initial bed level.
\end{abstract}

\section{INTRODUCTION}

Scour around the foundations of bridge piers is one of the major causes of serious damage to bridges (e.g. Tsujimoto et al., 1987). Since most rivers in Japan have been under severe bed degradation, it can be considered that there are many bridge piers at risk of exposure of its foundation during floods. Considerable understanding of flow and scour around a cylindrical pier has been achieved by a great many experimental research works over a long time. Previous scour investigators mainly focused on the scour around piers of uniform horizontal crosssection geometry and did not consider the effects of foundation geometry. In practice, foundations often exposed to flow and constitute a significant part of the obstruction that causes local scour.

Several investigations are available those describe the scour around piers of nonuniform geometry in consideration of the foundation. However, most of them focus on the formulation of maximum scour depth equations (e.g. Melville \& Raudkivi, 1996) or the analytical modeling of the scour depth (e.g. Tsujimoto et al., 1987; Lu et al., 2008). Few investigators have described the mechanism of scour at a pier with foundation. Little is known about the effect of foundation depth on scour process. Further experimental investigations concerning the sediment transport around a nonuniform pier are needed for a deeper understanding of the mechanism of local scour. The purpose of this study is to examine the influence of foundation depth 
on the process of the scour development and sediment transport around a pier with foundation.

\section{EXPERIMENTAL SETUP}

Experiments were conducted in a flume $12 \mathrm{~m}$ in length, $0.4 \mathrm{~m}$ wide and $0.4 \mathrm{~m}$ deep. Scouring tests were carried out in a sediment recess section situated $7.5 \mathrm{~m}$ from the inlet. The recess was $2.5 \mathrm{~m}$ in length, $0.4 \mathrm{~m}$ wide and $0.14 \mathrm{~m}$ deep. Refer to Umeda et al. (2008) for detailed description on the flume setup. A uniformly graded fine sand of mean diameter $d_{50}=0.17 \mathrm{~mm}$ was used to simulate the process of scour and sediment transport for a bed of cohesionless sediment. A model of a bridge pier with foundation shown in Figure 1 was mounted on the flume bed on the centerline. The pier was simply modeled with a slender cylinder $(D=30 \mathrm{~mm})$ founded on a large cylinder $\left(D^{*}=50 \mathrm{~mm}\right)$. The foundation top elevation $Z$ shown in Figure 1 is measured from the initial bed level and is positive if the top of the foundation is below the initial bed level and vice versa. Scouring tests were performed under a clear water scouring condition. The mean water depth $h=0.147 \mathrm{~m}$, the mean flow velocity $U_{m}=0.17 \mathrm{~m} / \mathrm{s}$, the mean water temperature was $25^{\circ} \mathrm{C}$. The Froude number was $F_{r}=0.14$. The pier Reynolds number was $R e_{D}=5700$. While the Shields parameter estimated from the velocity profile of undisturbed flow was $\theta_{0}=0.04$, the critical Shields parameter for the mobilization of the sediment war $\theta_{c}=0.05$. The tests were run for 4 or 5 days until the variation in the scour depth was less than $5 \%$ of the pier diameter in the succeeding 24 hours.

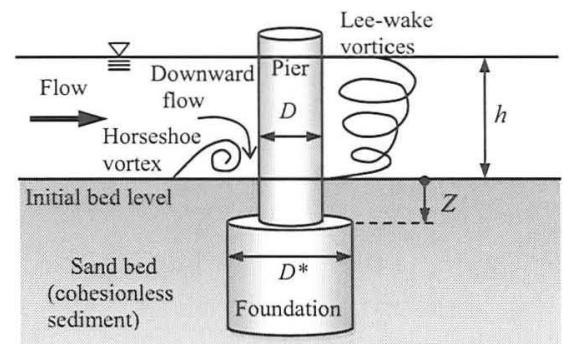

Figure 1. Model of bridge pier and relative foundation depth, $Z / D$.

\section{MEASURING TECHNIQUE}

Three-dimensional topography of the scoured bed (cf. Figure 4) was measured by digital stereo-photogrammetry. This technique is essentially based upon the concept of triangulation, in which three-dimensional object points can be determined from corresponding image points from at least two perspectives. This technique can determine scoured bed elevations around the pier with foundation. Four perspectives were taken from different directions to provide four stereo-pairs of images for accurately estimating the bed geometry near the pier (cf. Umeda et al., 2008). The images were taken, after shutting off and trapping water in the flume.

To validate the accuracy of the stereo-photogrammetric system on an underwater condition, initial tests were carried out by using the calibration target 
Table 1. Accuracy of the stereo-photogrammetric system on the underwater condition for $0.15 \mathrm{~m}$ in depth.

\begin{tabular}{ccccc}
\hline & $\begin{array}{c}\text { Estimation } \\
(\mathrm{A}) \mathrm{mm}\end{array}$ & $\begin{array}{c}\text { Measurement } \\
(\mathrm{B}) \mathrm{mm}\end{array}$ & $\begin{array}{c}\text { Absolute error Rate of error } \\
(\mathrm{C}=|\mathrm{A}-\mathrm{B}|) \mathrm{mm}(\mathrm{D}=100 \mathrm{C} / \mathrm{A}) \%\end{array}$ \\
\hline Horizontal & 53.7 & 54.0 & 0.3 & 0.6 \\
dimensions & 236.7 & 237.0 & 0.3 & 0.1 \\
$\mathrm{Xa}$ & 295.9 & 296.0 & 0.1 & 0.0 \\
& 383.7 & 384.0 & 0.3 & 0.1 \\
\hline Vertical & 24.8 & 25.2 & 0.5 & 1.9 \\
dimensions & 50.6 & 51.1 & 0.6 & 1.1 \\
Za & 75.8 & 75.0 & 0.7 & 1.0 \\
& 100.2 & 99.4 & 0.7 & 0.7 \\
\hline
\end{tabular}

whose dimensions were known with an uncertainty of $0.5 \mathrm{~m} \pm 0.2 \mathrm{~mm}$. The target was set in the underwater of $0.15 \mathrm{~m}$ in depth. Table 1 shows the comparison between the dimensions estimated by the photogrammetry system and the dimensions measured by rulers. Table 1 suggests the photogrammetry system can determine the horizontal and vertical coordinates with high accuracy. The accuracy of estimating the horizontal coordinates is better than that of estimating the vertical coordinates. The system can estimate the vertical coordinates with an accuracy of better than 1.0 $\mathrm{mm}$. It was found that the system was adaptable to estimating underwater topography of scour around the cylinder with high accuracy.

\section{EXPERIMENTAL RESULTS AND DISCUSSION}

\section{(1) Equilibrium scour depth}

Figure 2 shows the equilibrium scour depth as function of relative foundation depth $Z / D$. The equilibrium scour depth for a pier with foundation normalized with that for the upper uniform pier $S_{e} / S_{e D}$ is plotted on the ordinate. Two series' of experimental results obtained by Chabert \& Engeldinger (1956) and Melville \&

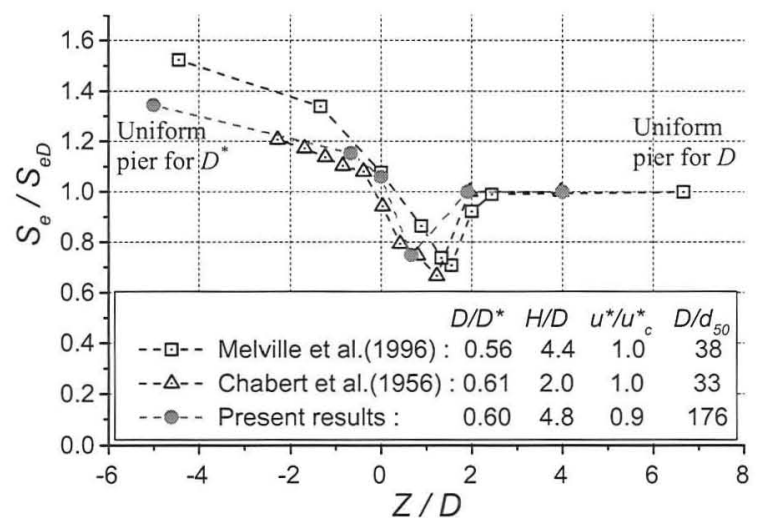

Figure 2. Equilibrium scour depth normalized with that of the uniform pier as function of relative foundation depth. 
Raudkivi (1996) for the threshold condition between clear water scour and live bed scour are also included in Figure 2 for comparison with the results of this study. Although there are some differences in experimental conditions as shown in Figure 2, the trend in the three data series is similar. When the foundation depth is larger than the scour depth for the upper uniform pier $\left(Z / D>S_{e D} / D \approx 1.9-2.4\right.$ for these case), the scour depth is the same as that for the uniform pier. The scour depth decreases with decreasing foundation depth when the foundation depth becomes less than the scour depth for the uniform pier. The reduction in scour depth due to the presence of the foundation reaches a maximum when the foundation depth is comparable with the diameter of the upper pier $(Z / D=1-1.5)$. Thereafter, the scour depth increases with decreasing foundation depth. As the foundation protrudes above the initial bed level $(Z / D<0)$, the scour depth increases and approaches that for the downward uniform pier with $D^{*}$ in diameter, i.e. the scour depth for the foundation alone.

\section{(2) Time evolution of the scour depth}

The time evolution of the scour depth normalized with the pier diameter $S / D$ is shown in Figure 3. The depth was measured at the front edge of the pier, relative to the initial bed level. For $Z / D=0.67$, the scour depth rapidly increases to the level of the top of the foundation, staying at that depth until about 5 hours into the experiment. Subsequently, the scour depth increases again, gradually approaching the equilibrium depth. For $Z / D=0$, the progress of the scour ahead of the pier is initially prevented due to the presence of the top of the foundation and the scour depth then increases to the equilibrium depth. Although the initial increment of the scour depth for $Z / D=-0.67$ is between $Z / D=0.67$ and $Z / D=0$, the equilibrium scour depth becomes the largest.

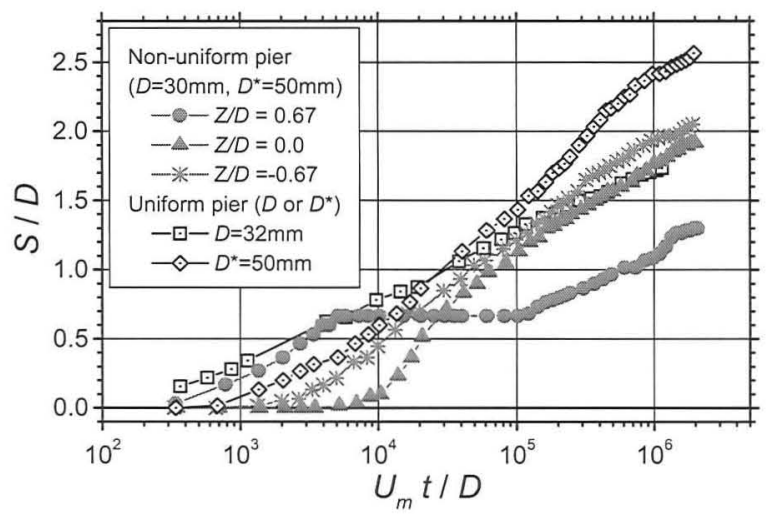

Figure 3. Time variation of scour depths for uniform and non-uniform piers.

\section{(3) Scour topography and sediment transport rate}

Figure 4 shows the time evolution of the bed topography during scour development for the pier with foundation of $Z / D=0.67$. The negative elevation of 

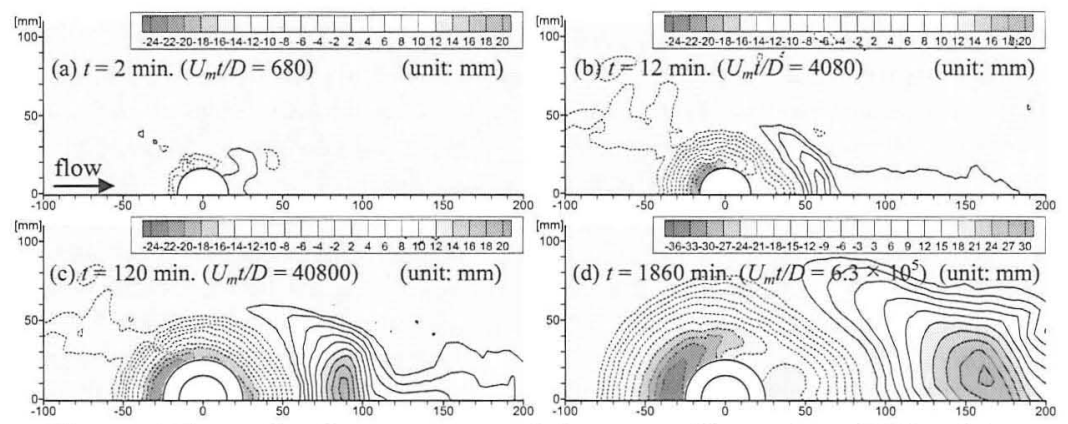

Figure 4. Scour development around the non-uniform pier of $Z / D=0.67$.

the scoured bed is denoted by dotted contour lines. The scour process around the pier is in the same way that scour develops around a uniform pier until the foundation expose at the surface of the riverbed (e.g. Umeda et al., 2008). The scour starts at the shoulders of the pier (i.e. $45^{\circ}$ from the forward stagnation point), and then the scouring enlarges to the surrounding area along the surface of the pier. Some of the eroded sediment drifts downstream, resulting in deposition of the sediment behind the pier base. As the scour progresses to the level of the top of the foundation, the development of the scour depth is limited and the scour hole formed around the pier keeps on expanding to the horizontal directions. This is mainly because the horseshoe vortex in front of the pier and the shedding vortices behind the pier continue to lift sediment, which is supplied by the sliding of sediment on the slope of the scour hole. Subsequently, the scour reaches the rim of the foundation and the scour depth increases again due to the effect of the horseshoe vortex and the wake vortices. The scour hole around the pier with foundation becomes an inverse truncated cone in shape and the shape of the scour hole is maintained during further scour development (Figure 4 (b)-(d)). The mound of the deposited sediment also appears as some part of the eroded sediment is fed into the downstream of the scour hole. The sediment mound moves to downstream and enlarge gradually. The height of the sediment mound is finally comparable with the depth of the scour hole.

Figure 5 shows the net sediment transport rate estimated with variation in the bed elevation for $Z / D=0.67$, according to the method supposed by Izumiya and Uchiyama (1992). The sediment transport rate $q_{i}$ was calculated by using the Helmholtz theorem and the mass balance of the sediment:

$$
\frac{\partial z_{b}}{\partial t}=-\frac{1}{1-n} \frac{\partial q_{i}}{\partial x_{i}} \quad(i=1,2)
$$

where $z_{b}$ is the bed level; $t$ is time; $n$ is the porosity of the bed; $x_{i}$ is the horizontal coordinates. It is well-known that any vector field can be resolved into the sum of an irrotational vector field and a solenoidal vector field (Helmholtz decomposition). The sediment transport rate $q_{i}$ estimated in this study corresponds to the irrotational component, which directly affects variation in the bed elevation. It is found in the figure 5 that the vectors of the sediment transport rate tend to be diverged from erosion area and converged into deposition area. The magnitude of $q_{i}$ increases with 

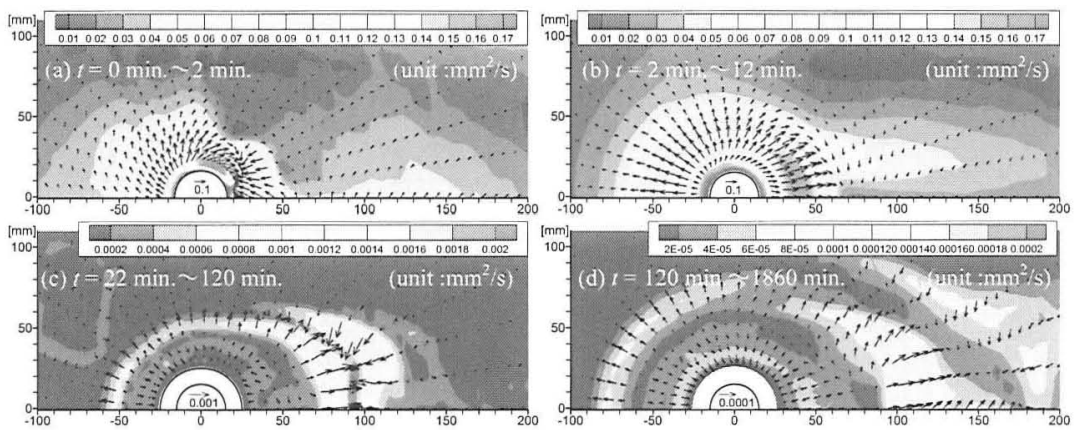

Figure 5. Sediment transport rate estimated with variation in the bed elevation $(Z / D=0.67)$.

increasing gradient of time-variation in the bed level and tends to be reduced in the scour process. While the sediment transport rate reaches a peak near the side edge of the pier during an initial stage of the scour process (Figure 5 (a)), the location of the peak sediment transport rate shifts to downstream of the pier when the scour hole developed around the pier (Figure 5 (b) and (c)). The sediment transport vectors during the initial stage have a similarity in distribution to the near-bed velocity reported in existing literatures (e.g. Sahin et al., 2007). The distribution of the vectors also consists with the typical motion of the sediment observed in this experiment.

For $Z / D=0.0$, where the elevation of the top of the foundation correspond to the initial bed level, the time evolutions of the bed topography and the sediment transport rate are shown in Figure 6 and Figure 7. It is seen that the sediment transport and scour during the initial stage of the scour process are dominant in the wake of the pier. The scour starts in the downstream of the pier and then a pier of depressions is gradually formed in the wake. Some part of the eroded sediment is deposited on the downstream of the depressions. The lee-wake vortices sweep, trap and eject an amount of sediment from the depressions. Most of the sediment ejected by the wake vortices is transported to far downstream of the pier. In contrast, the
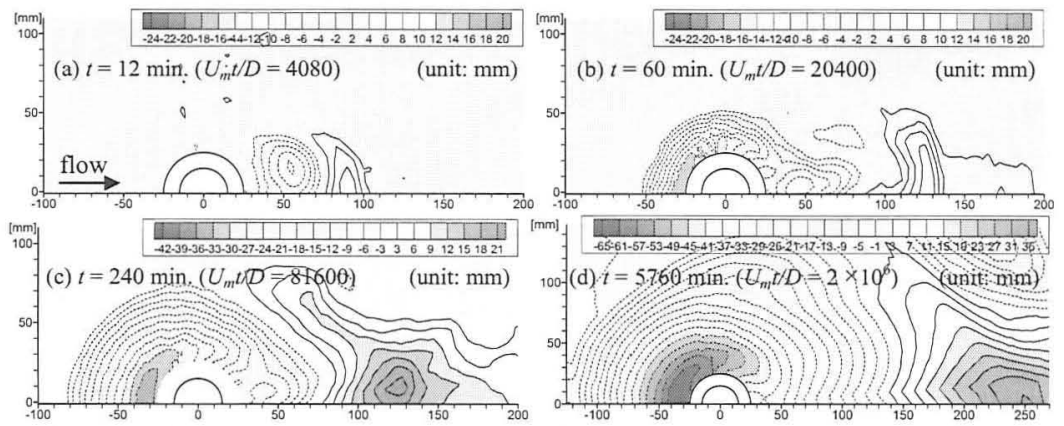

Figure 6. Scour development around the non-uniform pier of $Z / D=0.0$. 

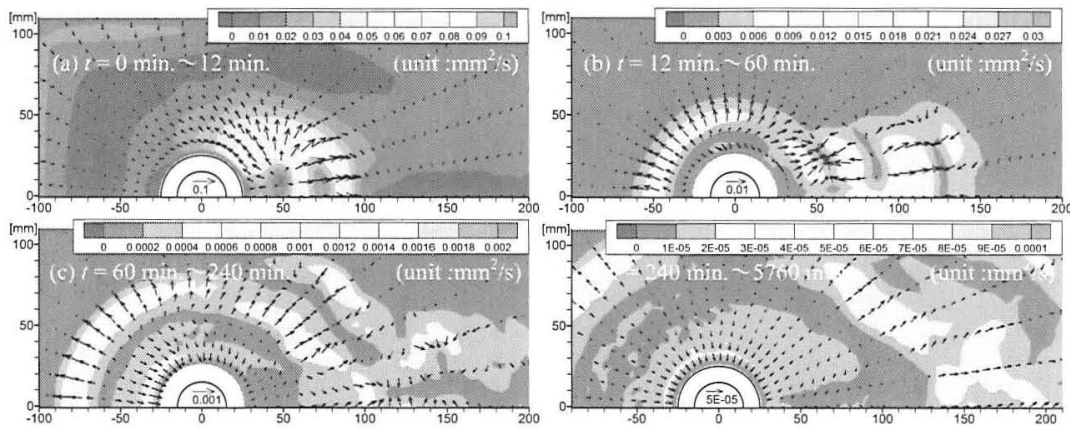

Figure 7. Sediment transport rate estimated with variation in the bed elevation $(Z / D=0.0)$.

initial progress of the scour upstream of the pier is considerably slower due to the existence of the top of the foundation. The flow accelerated by the contraction of the main flow around the pier starts to sweep the sediment along the rim of the foundation. And then the depressions formed at the shoulders of the foundation gradually enlarge to the surrounding area, resulting in the scour hole being developed.

For $Z / D=-0.67$, where the top of the foundation is above the initial bed level, the bed topography and the sediment transport rate are shown in Figure 8 and Figure 9. The scour starts at the shoulders of the foundation, and then the scouring enlarges to the surrounding area along the rim of the foundation. Some of the eroded sediment drifts downstream, resulting in the sand ripples being developed on the downstream of the foundation (Figure 8 (a)). As the sand bed ahead of the foundation is eroded to a certain depth, the horseshoe vortex develops in the scour hole formed around the foundation. Since the horseshoe vortex in front of the foundation lifts volumes of the sediment from the scour hole, the scour hole rapidly increases in size and in depth during the middle stage of the scour process (Figure 8 (b)). It is found that the net sediment transport rate $q_{i}$ increases around the brim of the scour hole (Figure 9 (b) and (c)). There is some part of the eroded sediment swept downstream as bed-load
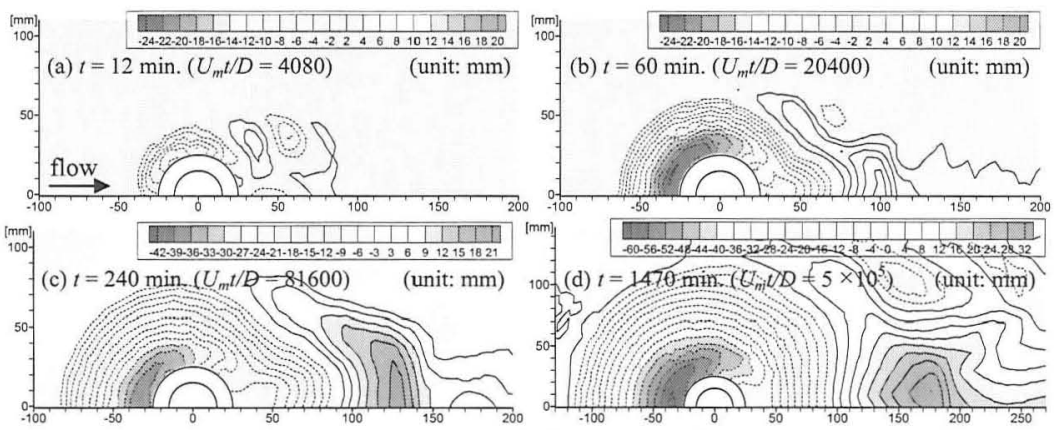

Figure 8. Scour development around the non-uniform pier of $Z / D=-0.67$. 

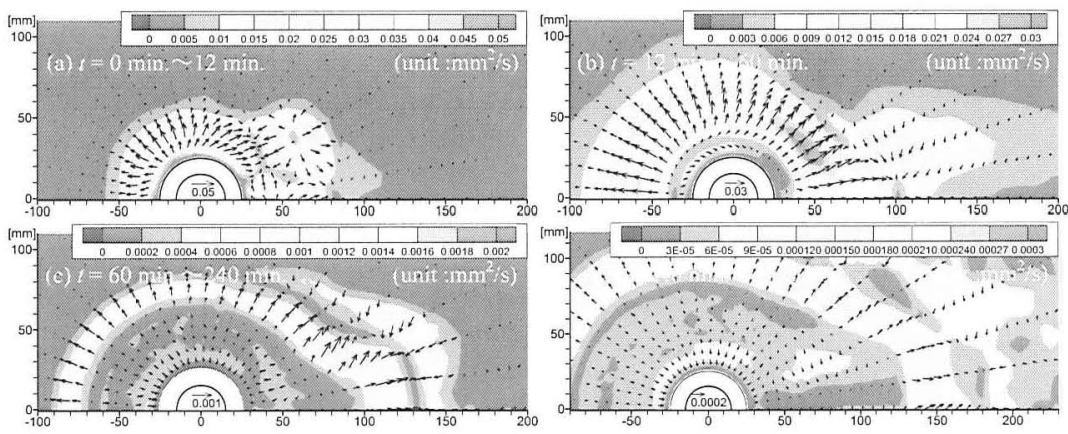

Figure 9. Sediment transport rate estimated with variation in the bed elevation $(Z / D=-0.67)$.

due to the contraction of the flow near the downstream slope of the scour hole. The bed-load leads to formation of the sediment mound downstream of the scour hole. While the initial and middle scour is mainly induced by the flow contraction and the horseshoe vortex respectively, the vortex shedding in the wake also plays an important role in the development of the scour hole as the scour progresses. The wake vortices continue to eject volumes of the sediment from the downstream part of the scour hole. The sediment is transported downstream as suspended-load, which is convected and diffused by time-dependent flow in the wake. As the scour approaches equilibrium stage, the bed-load disappears first and the suspended-load induced by the horseshoe vortex then disappears. The suspended sediment transport by the wake vortices was kept in the experiment.

\section{(4) Volumes of erosion and deposition}

Figure 10 shows the time evolutions of the erosion and deposition volumes of the sediment around the piers of $Z / D=0.67,0.0$ and -0.67 . The volumes are normalized with the cube of the pier diameter. The erosion and deposition volumes correspond to the volume of the near-pier scour hole $V_{\mathrm{e}}$ and the volume of the prime sediment mound behind the scour hole $V_{\mathrm{d}}$ respectively. The negative volume means erosion. Like the scour depths, the volumes increase with time, but the rates of increase gradually decrease. The deposition volume early achieves an equilibrium value in comparison with the erosion volume. The erosion volume is influenced by the relative foundation depth $Z / D$. For these cases, the erosion volumes $V_{e}$ increase with decreasing $Z / D$. While the normalized erosion volume $V_{e} / D^{3}$ for $Z / D=-0.67$ reaches about 45 at the end of the test, $V_{e} / D^{3}$ for $Z / D=0.67$ is reduced to almost onehalf. The influence of the relative foundation depth on the deposition volume of the sediment is not significant in these cases. The maximum volume of the deposition $V_{d} / D^{3}$ is about 10 . The sum of the two volumes $\left(V_{t}=V_{\mathrm{c}}+V_{\mathrm{d}}\right)$ represents the volume of sediment transported downstream of the deposition mound. While most of $V_{t}$ can be considered as the suspended-load related to the vortices, most of $V_{d}$ can be considered as the bed-load related to the contraction of the main flow. It is found in these cases that the ratio of the deposition volume to the erosion volume decreases as 

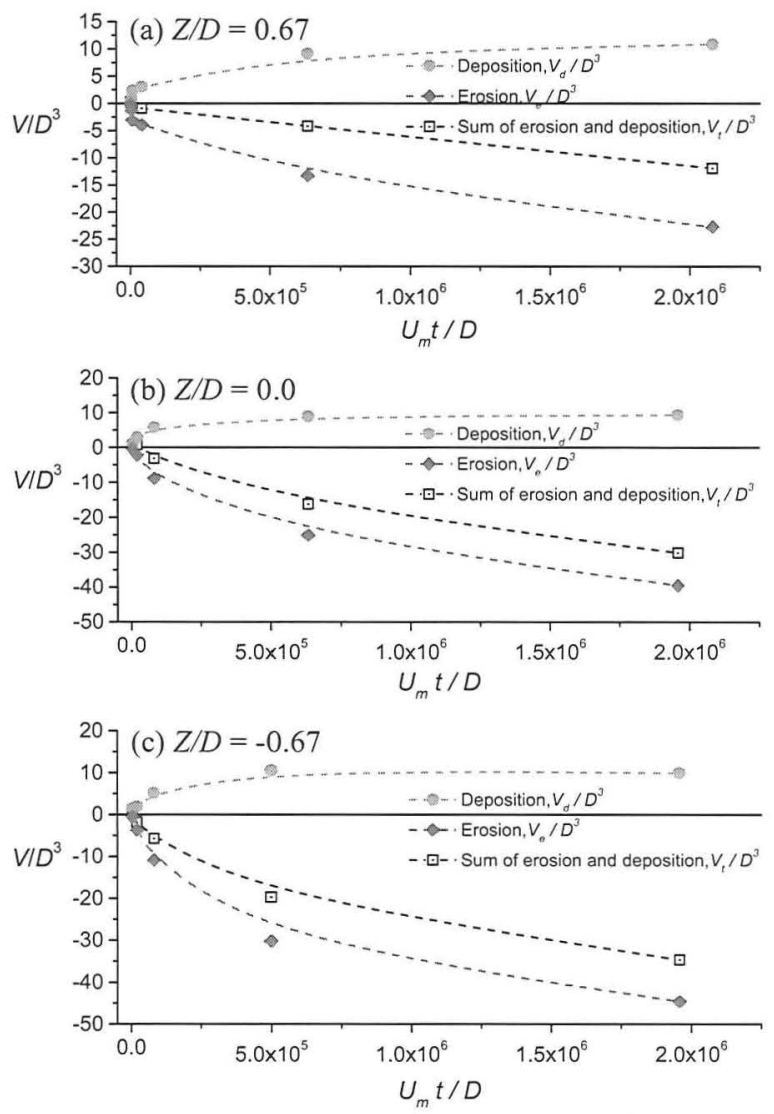

Figure 10. Time variation of the erosion and deposition volumes of the sediment around the piers of $Z / D=0.67,0.0$ and $\mathbf{- 0 . 6 7}$.

scour progresses and tends to increase with increasing $Z / D$. The ratio is calculated in the range of 0.2 to 0.4 . It can be seen that the suspended sediment transport becomes more significant as the foundation of the pier protrudes from an initial bed level.

\section{CONCLUSIONS}

The following conclusions are based on this experiment on the process of the scour development and sediment transport around a pier with foundation of varying depth from an initial bed level.

The equilibrium scour depth, scour process and sediment transport are influenced by the relative foundation depth $Z / D$. For $S_{e D} / D>Z / D>0$, the equilibrium scour depth is less than that of a uniform pier $S_{e D}$. The reduction in scour 
depth due to the foundation is significant when the foundation depth is comparable with the diameter of the upper pier. For $Z / D=0$, the scour depth is not very different from $S_{e D}$. However, the process of the scour development is different from that of a uniform pier. One of the features of the process is that the sediment transport induced by lee-wake vortices is stronger than that by the horseshoe vortex and the contraction of main flow during the initial stage of the scour process. For $Z / D<0$, the scour depth is larger than that of a uniform pier. The first scour takes place at the shoulders of the foundation and the scouring then enlarges to the surrounding area along the rim of the foundation, resulting in the scour hole being developed.

The influence of $Z / D$ on the deposition volume of the sediment is not significant in these cases. The maximum volume of the deposition is about 10 times the cube of the pier diameter. The erosion volume tends to increase with decreasing $Z / D$ and is estimated in the range of 23 to 45 times.

These experimental results can be useful for understanding of scour mechanism as well as for calibration of a mathematical modeling. However, there is still a great need to obtain understanding of live-bed scouring and scale effects inherent in laboratory flume experiments.

\section{REFERENCES}

Chabert, J. and Engeldinger, P. (1956). "Etude des affouilements autour des piles des ponts (Study of scour at bridge piers)." Rep., Laboratoire National d'Hydraulique, France.

Izumiya, T. and Uchiyama, T. (1992). "Estimation method of two-dimensional vectors of the sediment transport rate with a potential function for the sediment transport." Proc. 39th of Coastal Engineering in Japan, JSCE, vol. 39: 321-325 (in Japanese).

Lu, J.Y., Hong, J.H., Lee, J.J. and Shi, Z.Z. (2008). "Temporal variation of scour depth at nonuniform cylindrical pier with unexposed foundation." Proc. of 4th Int. Conf. on Scour and Erosion, (CD-ROM): 174-179.

Melville, B.W and Raudkivi, A.J. (1996). "Effects of foundation geometry on bridge pier scour." J. Hydraulic Engineering, 122(4): 203-209.

Melville, B.W. and Yee, M.C. (1999). "Time scale for local scour at bridge piers." J. Hydraulic Engineering, 125(1): 59-65.

Sahin, B., Ozturk, N.A. and Akilli, H. (2007). "Horseshoe vortex system in the vicinity of the vertical cylinder mounted on a flat plate." Flow Measurement and Instrumentation, Vol. 18: 57-68.

Tsujimoto, T., Murakami, S., Fukushima, T. and Shibata, R. (1987). "Local scour around bridge piers and its protection works." Mem. Fac. Technol. Kanazawa Univ., Japan, Kanazawa, vol. 20, No.1: 11-21.

Umeda, S., Yamazaki, T. and Ishida, H. (2008). "Time evolution of scour and deposition around a cylindrical pier in steady flow." Proc. of 4th Int. Conf. on Scour and Erosion, (CD-ROM): 140-146. 